\title{
Abordagem interdisciplinar dos conceitos relacionados a depressões doliniformes na Planície do Araguaia, Brasil
}

\author{
Oscar Eduardo Paez Manchola ${ }^{1 \star}$ (D), Fernando de Morais $^{1}$ (D), Karylleila dos Santos Andrade ${ }^{2}$ (D) \\ 1 Programa de Pós-graduação em Ciências Ambientais, Campus de Palmas, Avenida NS 15, Quadra 109 Norte | Plano \\ Diretor Norte, Complexo de Pesquisa e Pós-graduação Prof. Dr. Lamadrid, Sala 13, 1º andar, Palmas, TO, 77001090. \\ 2 Universidade Federal do Tocantins, Plano Diretor Norte, Centro, Palmas, TO - Brasil, 77000000. \\ * E-mail para correspondência: oscarepaezm@gmail.com
}

Recebido em 27 de abril de 2020.

Aceito em 19 de maio de 2021.

Publicado em 15 de junho de 2021.

Resumo - Na Planície do Araguaia, depressões circulares cobertas com vegetação são denominadas por diversas etimologias. Não obstante, o uso destes conceitos difere em função do agente denominador e na aplicação às diversas áreas do conhecimento. Por este motivo, o objetivo deste trabalho foi analisar a relação dos designativos toponímicos, de natureza acadêmica, utilizados para o referente "depressão doliniforme". Para isto, foi utilizada a classificação toponomástica de designativos e a aplicação de Análises de Redes Sociais ARS. Foram identificados 367 significados de 66 trabalhos acadêmicos, no período entre 1985 e 2019, sendo as designações mais frequentes: ipuca (64,3\%), impuca (25,3\%) e dolina $(6,8 \%)$ motivadas pela ideia de fragmentos florestais inundados. Por meio da ARS foi possível verificar a relação semântica destes conceitos, onde a designação ipuca representou 92\% de vínculos conectados a diferentes áreas do conhecimento - interdisciplinar, já a tipologia impuca apresentou $88 \%$ dos vínculos associados à fitossociologia - disciplinar. Conclui-se que, na aplicação interdisciplinar, ipuca e impuca estendem seu significado semântico de cunho vegetal para estruturas cársticas denominadas dolinas, sendo necessária, portanto, a distinção semântica quanto à morfogênese do substrato subjacente dos fragmentos florestais inundados, pois a desconsideração disto implicaria em impactos na preservação e manejo destas estruturas.

Palavras-chave: Dolina. Ipuca. Impuca. Toponímia. Análise de rede social.

\section{Interdisciplinary approach to concepts related to doline-like features in the Araguaia Plain, Brazil}

Abstract - In the Araguaia Plain, circular depressions covered with vegetation are often referred to by diverse etymologies. However, the use of these concepts differ depending on the denominating subject and the contextualized meaning in different areas of knowledge. For this reason, the objective of this work was to analyze the relationship of toponymic designations of academic studies that are associated with the reference: "doline-like features". For this, toponomastic methods of classifying projects and Social Networks Analysis-SNA applications were used. Based on those, 367 meanings in 66 academic studies, in the period from 1985 to 2019, were identified, with the most used designations being: ipuca (64.3\%), impuca (25.3\%) and doline $(6.8 \%)$, referring to the idea of a flooded forest fragment. By applying the SNA method, 
it was possible to verify the semantic relationship, where the designation ipuca represents $92 \%$ of the links connected to different areas of knowledge (interdisciplinary) and the typology impuca registered $88 \%$ of the links associated with phytosociological studies (disciplinary). It can be concluded that in the interdisciplinary application ipuca and impuca extend a semantic meaning of vegetable origin to karstic structures denominated dolines; therefore, making a semantic distinction regarding the morphogenesis of the underlying substrate of the flooded forest fragments is needed, as failing to do so could impact the conservation and management of these structures.

Keywords: Doline. Ipuca. Impuca. Toponymy. social network analysis.

\section{Abordaje interdisciplinar de conceptos relacionados a depresiones doliniformes en la Planicie del Araguaia, Brasil}

Resumen - En la Planicie del Araguaia, depresiones circulares cubiertas con vegetación son denominadas por diversas etimologías. No obstante, el uso de estos conceptos difiere en función del agente denominador y en la aplicación para las diversas áreas del conocimiento. Por este motivo, el objetivo de este trabajo fue analizar la relación de los designativos toponímicos, de naturaliza académica, utilizados para el referente "depresión doliniforme". Para esto, fue utilizada la clasificación toponomástica de designativos y la aplicación de Análisis de Redes SocialesARS. Fueron identificados 367 significados de 66 trabajos académicos, en el periodo de 1985 a 2019, siendo las designaciones más frecuentes: ipuca (64,3\%), impuca $(25,3 \%)$ y dolina $(6,8 \%)$ motivadas por la idea de fragmentos forestales inundados. Por medio de la ARS fue posible verificar la relación semántica de los conceptos, donde la designación ipuca representó 92\% de vínculos conectados a diferentes áreas del conocimiento (interdisciplinar), ya la tipología impuca presentó $88 \%$ de los vínculos asociados a la fitosociología (disciplinar). Se concluye que, en la aplicación interdisciplinar, ipuca e impuca extienden su significado semántico de cuño vegetal para estructuras kársticas denominadas dolinas, siendo necesaria, por tanto, la distinción semántica cuanto a la morfogénesis del substrato subyacente de los fragmentos forestales inundados, pues la desconsideración de esto implicaría en impactos en la preservación y manejo de estas estructuras.

Palabras clave: Dolina. Ipuca. Impuca. Toponimia. Análisis de redes sociales.

\section{Introdução}

A linguagem, como elemento pluri, multi e interdisciplinar, é essencial para a comunicação. Ela estabelece uma relação intrínseca com a cultura, sociedade e o lugar. Essa interação social, realizada por meio de um sistema de signos linguísticos, permite, dentre outros aspectos, nomear lugares (topônimos ${ }^{1}$ ). É fundamental compreender esses nomes a partir dos diferentes significados, olhares e áreas de atuação, pois, por se organizarem de maneira dinâmica, constantemente se (re)inventam no tempo e no espaço, sobrepondo-se a valores socioculturais, identitários, econômicos, ambientais, políticos e, até mesmo, religiosos. No nosso entender,

1 A Onomástica é a ciência que estuda os nomes próprios. Ela se subdivide em Toponomástica, disciplina que estuda os nomes de lugares, e em Antroponomástica, disciplina que estuda os nomes de pessoas. A toponímia é o conjunto de nomes de lugares e topônimo é o próprio nome de lugar. 
reconhecemos o nome de lugar como sendo um patrimônio linguístico e cultural, testemunho de uma comunidade. Materializado e corporificado, ele é um produto e o reflexo social e cultural da cosmovisão de um grupo.

A partir de uma visão interdisciplinar, a Toponímia estabelece o sentido de unidade diante dos diversos saberes, pois, para estudar os nomes de lugares, é preciso levar em conta as várias áreas do conhecimento. Não se pode compreender um topônimo a partir de um único olhar disciplinar, uma vez que ele agrega vários aspectos e de diversas áreas. O topônimo é o elemento funcional que o homem utiliza para humanizar a paisagem, representando entidades geográficas determinadas que retratam não somente um léxico linguístico, mas sim a cultura do seu povo, sua história e sua relação com a natureza (Fonseca 1997).

Ao organizar culturalmente o espaço geográfico, por meio de topônimos, cria-se uma diversidade de denominações que podem evoluir ao longo do tempo (diacronia) ou sofrer variações regionais em função de diferentes estruturas linguísticas utilizadas (sincrônica). Dessa forma é necessário reconhecer as nomenclaturas e significados utilizados para o mesmo espaço físico ou realidade geográfica (referente).

O estudo do meio ambiente não pertence a nenhuma ciência ou disciplina específica. A complexidade dos processos envolvidos transcende para realidades físicas, biológicas, sociais e culturais, sendo necessária a reunião de saberes (Nunes e Andrade 2012). Desse modo, a integração de diferentes áreas do conhecimento deve ser utilizada como resposta aos crescentes impactos ambientais (Teles e Morais 2019).

Na Planície do Araguaia, rebaixamentos do terreno (depressões) de forma circular ou ovalada (doliniformes) assumem várias denominações, usadas academicamente em diferentes áreas do conhecimento. Em algumas situações, elas apresentam dificuldades semânticas quanto à aplicação pelo agente denominador, origem da língua e significado intrínseco (algumas apresentam significados universalmente aceitos e outras apresentam ampliação semântica).

Com base nisto, o objetivo principal deste trabalho será: analisar, sob o viés de várias áreas do conhecimento, os designativos toponímicos de natureza acadêmica e (inter)disciplinar utilizados em referência à "depressão doliniforme", localizados na Planície do Araguaia, considerada como principal unidade geomorfológica dos processos relacionados à formação do relevo.

\section{Material e métodos}

Para atingir o objetivo proposto, este trabalho foi executado em três etapas: Caracterização da área de estudo; Classificação de dados coletados com base na ficha lexicográfica-toponímica e Verificação de resultados em Redes Sociais de Análises.

\section{Caracterização da área de estudo}

A Planície do Araguaia está localizada nos estados de Matogrosso, Tocantins e Goiás, possui uma extensão de 64.761,9 km² (Figura 1), sendo 30\% correspondente à Ilha Fluvial do Bananal formada por áreas potenciais para a conservação ambiental, como: o Parque Estadual do Cantão, Parque Nacional do Araguaia e Terras indígenas (etnias predominantes: Karajá, Javaé e Krahô-kanela) 
(Brasil 1981) (SEPLAN 2012). Atualmente, vivem no Parque do Araguaia, em terras indígenas, os povos Ava-Canoeiro, Karajá, Javaé e Tapirapé.

A unidade geomorfológica está inserida na bacia do Rio Araguaia, caracterizada como região ecotonal dos biomas Cerrado e Amazônico (Pinheiro e Dorna 2009). O clima de savana tropical e sua característica biogeográfica proporcionam habitats com alta diversidade de espécies, destacandose espécies com elevado grau de endemismo (adaptadas a variações sazonais dos cursos d'água). Estas características classificam a região como uma importante zona destinada à conservação (Kurzatkowski et al. 2015; Lopes et al. 2017).

Figura 1. Localização da área de estudo (Planície do Araguaia).

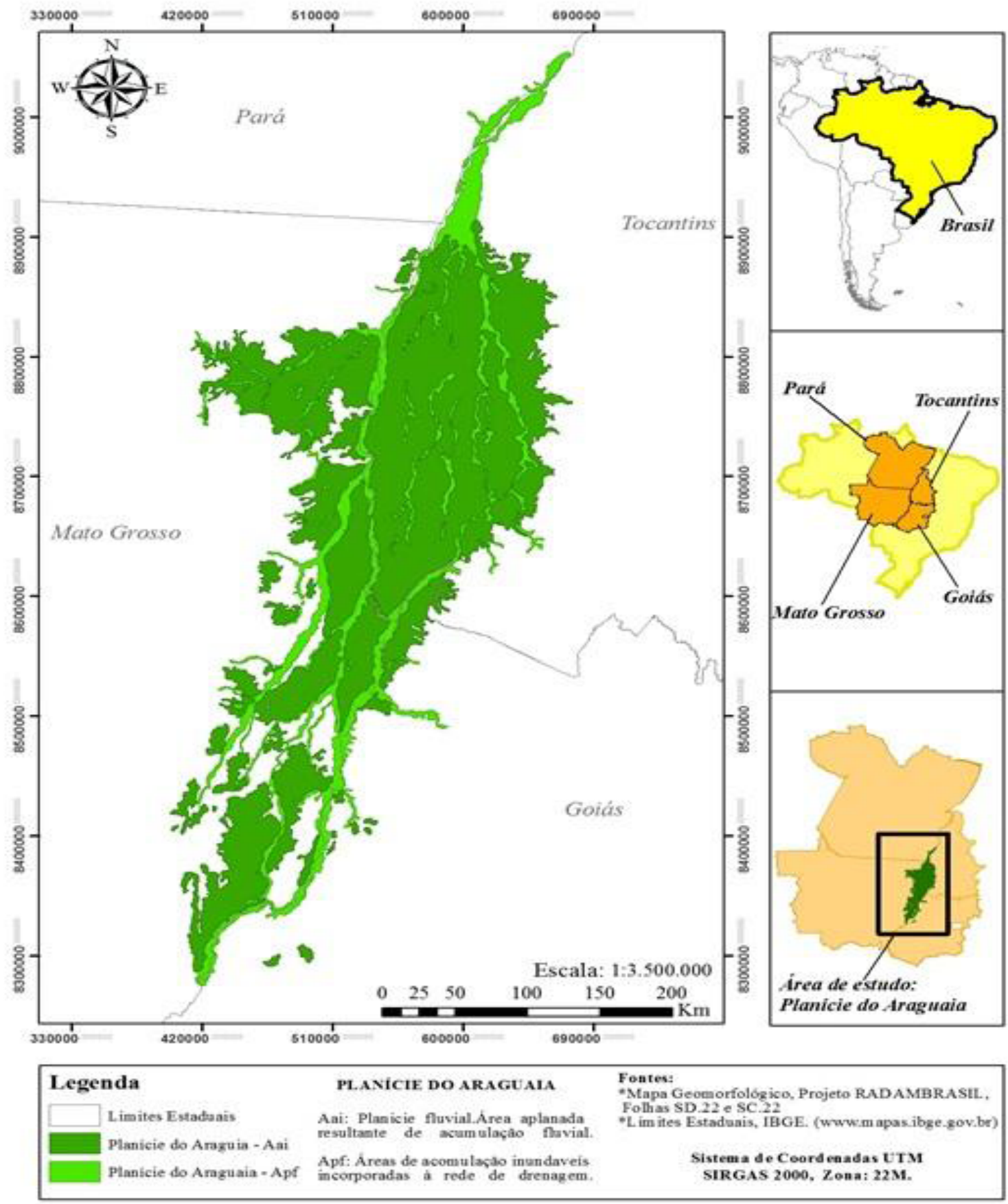


Sua caracterização geológica compreende, majoritariamente, dois ambientes: ao oeste, sedimentos Cenozoicos da Cobertura Sedimentar, compostos por pacotes areno-argilosos, muitas vezes, em estado avançado de laterização. Ao leste, sedimentos Neoproterozoicos da Formação Couto Magalhães, pertencentes ao Grupo Tocantins, compostos por filitos, ardósias, quartzitos, calcários e serpentinitos (Brasil 1981).

As características planas do terreno, os solos férteis e a abundância de recursos hídricos da região têm favorecido o desenvolvimento de intensas atividades agropecuárias. Nos últimos 20 anos, incentivos governamentais vêm sendo aplicados para aumentar a produção agropastoril em grande escala, acelerando o processo de desmatamento e a captação exacerbada de importantes cursos d'água (Rio Formoso e Rio Javaés), causando fortes reduções nas vazões dos rios e acentuada fragmentação dos corredores ecológicos próximas às unidades de conservação (MAPBIOMAS 2019; MagalhãesFilho et al. 2015; Morais et al. 2017; Moreira et al. 2019).

\section{Ficha lexicográfica-toponímica}

Para entender o processo gerativo da denominação de nomes próprios de lugares, foram analisados trabalhos acadêmicos realizados na Planície do Araguaia com o uso de topônimos (topos: lugar; onoma: nome), relacionados ao referente: "depressão doliniforme".

A análise dos dados foi realizada com base na ficha lexicográfica-toponímica, proposta por Dick (2004). Essa ficha, adaptada para este estudo (Tabela 1), permite organizar as informações essenciais do referente (entidade geográfica determinada) e distribuí-las em unidades lexicais (categorias), estatisticamente relacionadas às motivações toponímicas usadas no processo de nomeação (Dick 2004; Pocklington s.d).

Tabela 1. Elementos utilizados na ficha lexicográfica-toponímica, baseados em Dick (2004).

\begin{tabular}{|c|c|}
\hline Unidade lexical & Descrição \\
\hline Referente & Objeto real ou entidade concreta. \\
\hline Tipologia & $\begin{array}{l}\text { Sintagma toponímico simples, nome, termo ou conceito usado para o } \\
\text { referente. }\end{array}$ \\
\hline Motivação Toponímica & $\begin{array}{l}\text { Recorte de uma ideia, noção e/ou traço da realidade, de natureza física ou } \\
\text { humano/cultural, produzido a partir da intencionalidade do denominador. }\end{array}$ \\
\hline Taxeonomia & $\begin{array}{l}\text { Agrupamento macroestrutural que sintetiza os topônimos em categorias } \\
\text { baseadas nos processos de nomeação e motivação. }\end{array}$ \\
\hline \multirow{3}{*}{$\begin{array}{l}\text { Procedência do } \\
\text { conhecimento do } \\
\text { nomeador }\end{array}$} & $\begin{array}{l}\text { Empírico: Inferência sem análise metodológica, apenas pela observação, } \\
\text { hipóteses. }\end{array}$ \\
\hline & $\begin{array}{l}\text { Cientifico: Inferência adquirida pelo uso de métodos e comparação de } \\
\text { resultados, afirmação concreta. }\end{array}$ \\
\hline & $\begin{array}{l}\text { Popular: Inferência adquirida pelas tradições e saberes culturais de uma } \\
\text { determinada região ou grupo Cultural. }\end{array}$ \\
\hline
\end{tabular}

Fonte: (Dick 2004). 
As categorias taxeonômicas utilizadas neste estudo, foram descritas por Dick (1992) e se subdividem em: Natureza física (acidentes geográficos naturais) e Natureza Antropo-cultural (aspectos relacionados ao homem e sua cultura).

Além das informações semânticas descritas com base na ficha lexicográfica-toponímica (Dick 2004), foram classificadas também as características de cada trabalho acadêmico com relação: ao Tipo (artigo, tese, dissertação, monografia, livro, anais, relatório técnico); aos Autores(as); à Data da publicação; ao Título do trabalho; ao Tema principal; à Localização da área de estudo e às Referências.

\section{Rede interdisciplinar}

Para identificar o grau de interdisciplinaridade do referente "depressão dolinifome" em trabalhos acadêmicos, foi utilizado o método de análise de rede sociais (Social Network Analysis) para a detecção de comunidades disciplinares ou interdisciplinares por meio dos vínculos entre citações e temas abordados (Bordin et al. 2015). A visualização e a análise exploratória de dados foram realizadas no software livre Gephi 0.9.2.

A análise exploratória foi elaborada a partir do cruzamento das citações de cada autor e sua relação com os demais. Para tanto, foi elaborada uma matriz de adjacência, considerando os vínculos estabelecidos pelas citações entre os autores (arestas) e a quantidade de citações que recebeu determinado autor (nós). Todos os vínculos diretos foram classificados em Disciplinar ou Interdisciplinar: Citação entre autores com o mesmo tema - Disciplinar; e Citação entre autores de diferente tema - Interdisciplinar.

\section{Resultados}

\section{Ficha lexicográfica-toponímica}

Foram identificados 66 trabalhos acadêmicos (35 artigos, 11 dissertações, 11 anais, 7 teses, 1 livro e 1 relatório técnico), no período entre 1985 e 2019. Desses trabalhos, foram analisados 367 significados relacionados ao referente "Depressão doliniforme", localizados na Planície do Araguaia. Todos os significados do referente foram analisados com base no proposto por Dick (2004) e calculados por meio do software livre The R Project for Statistical Computing. Os resultados são apresentados na Figura 2. 
Figura 2. Percentual de Unidades lexicográficas identificadas para o referente "depressão dolinforme", descrito a partir de trabalhos acadêmicos realizados na Planície do Araguaia no período de 1985 a 2019.

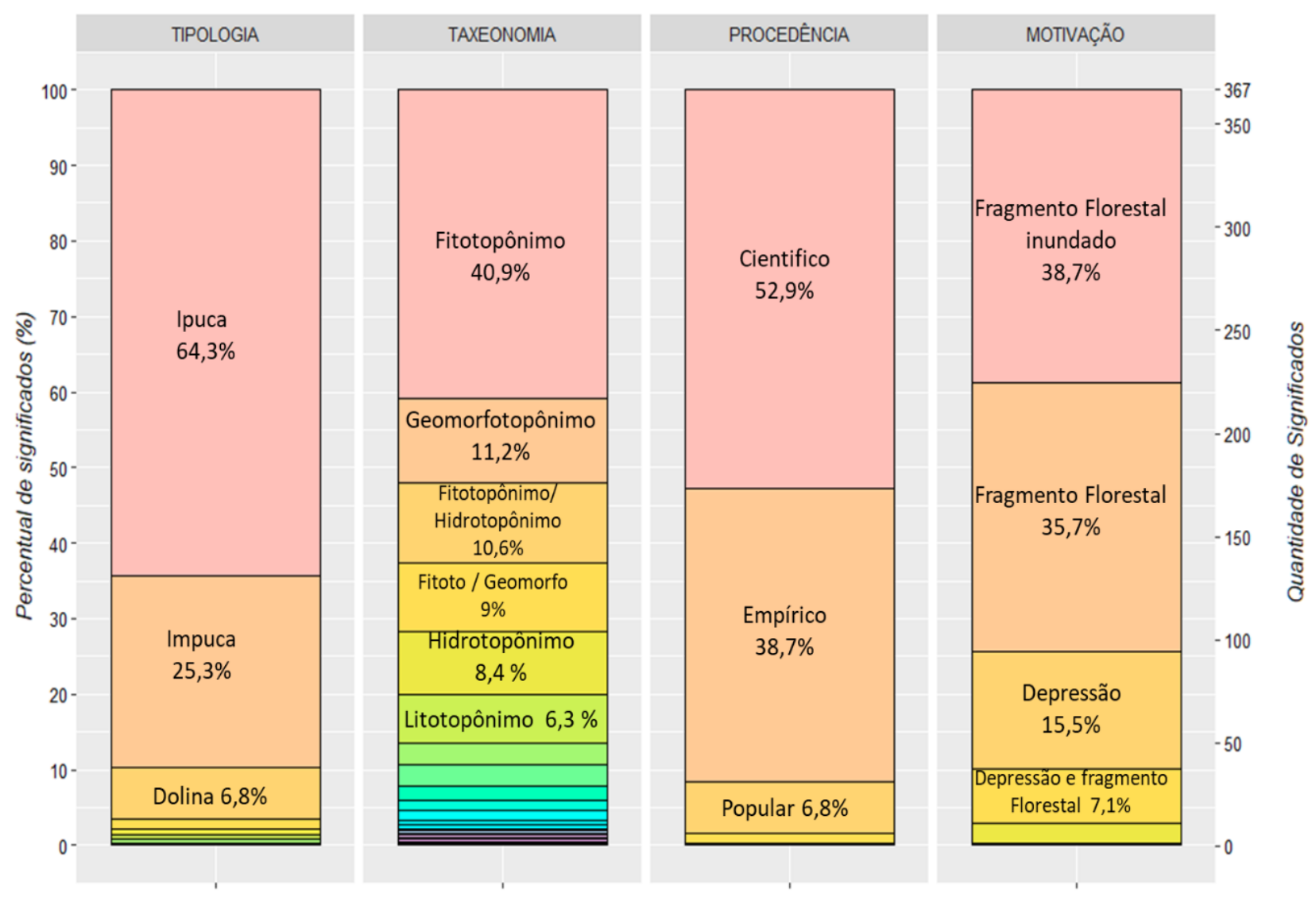

\section{Designações toponímicas (Tipologias)}

Foi observado que as designações toponímicas, mais utilizadas nos trabalhos acadêmicos na Planície do Araguaia, para o referente "depressão doliniforme", são: ipuca (64,3\%), impuca $(25,3 \%)$ e dolina (6,8\%). As duas mais frequentes, ipuca e impuca, são de etimologia indígena Tupi: y- 'água'; puca '1. fenda, racha, erosão; 2. Parar, cessar, passar (a chuva)'. (Tibiriça 1984) e y-puca 'água aberta; água que arrebenta' (Sampaio 1987). Essas acepções podem sofrer "alterações ao serem adaptadas a novas estruturas linguísticas (Fonseca 1997)". No caso de impuca, identificamos um processo de alteração fonética do termo ipuca, o qual faz parte do próprio uso da língua pelos falantes. Neste caso, em especial, ocorre um processo de nasalização ou nasalação, ou seja, a transformação de um fonema oral em um fonema nasal: /i/ > /ĩ/, sendo a transcrição gráfica impuca. Para este estudo, as designações toponímicas, ipuca, impuca e dolina, são consideradas como variantes linguísticas do referente "depressão doliniforme", uma vez que as distribuições das duas formas delimitam áreas específicas de ocorrência.

O primeiro registro acadêmico na Planície do Araguaia com o uso do topônimo impuca foi verificado no ano de 1985, pelo botânico e professor Dr. Gorge Eiten, no artigo titulado: Vegetation near Santa Teresinha, Ne Mato Grosso, no qual é caracterizado a vegetação que margeia o Rio Araguaia, definindo-a como Mata de Galeria. Ele faz uma distinção entre "outra 
parte da mata de galeria", ao afirmar: "this is impuca do rio or simply impuca" descrevendo-a como: uma "lower form of forest" (forma inferior de floresta), sazonalmente inundada, com arvores de 4 a 5 metros de altura, videiras entrelaçadas e arvores frequentemente espinhosas com baixa riqueza florística em comparação à Mata de Galeria de áreas mais elevadas (Eiten 1985).

Já o topônimo ipuca, foi apresentado academicamente em 1999, na dissertação de mestrado da geógrafa e professora Dra. Iracy Coelho Martins, titulada: "Diagnóstico ambiental no contexto da paisagem de fragmentos florestais naturais -ipucas- no município de Lagoa da Confusão, Tocantins". Nesse trabalho, ela ressalta a importância do fragmento florestal natural para equilíbrio ambiental, ao funcionarem como elo entre vários rios, córregos e lagoas, caracterizando as ipucas como fragmentos florestais homogêneos (indivíduos da mesma espécie), distribuídas em forma de "ilhas" que apresentam formas longilíneas e arredondadas em campos sujos e limpos. A maior parte delas possuem áreas até 5 hectares e algumas chegam a mais de 100 hectares de extensão. Sua constituição litológica refere-se a solos pouco profundos com alta influência do lençol freático, o que favoreceria a deposição de uma espessa camada de matéria orgânica e materiais finos como argila e silte no seu interior. A autora ressalta ainda que: "Apresentam-se em formas de dolinas, ou seja, pequenas depressões resultantes de processos de perda de água e ganho de matéria orgânica" (Martins 1999)

O topônimo dolina foi frequente em 5,2\% dos trabalhos acadêmicos, localizados na Planície do Araguaia. Essa designação foi introduzida internacionalmente pelo geografo Sérvio Jovan Cvijic, em 1893, como analogia a uma "pequena bacia hidrográfica" (Bondesan et al. 1992). Atualmente, dolina é mais usado por geomorfólogos europeus, já Sinkhole, considerada como variante lexical, é mais comum no norte de América e na literatura internacional (Gutiérrez et al. 2008).

Dolina ou "sinkhole" são topônimos que se referem a depressões naturais de ambientes cársticos que possuem formas elípticas ou circulares e funcionam como unidades hidrográficas (pontos de recarga), convergindo as águas superficiais para sistemas subterrâneos. Sua origem está relacionada à solubilidade de rochas (carbonáticas e não carbonáticas), por meio de processos de dissolução, colapso ou subsidência (Ford e Williams 2007).

\section{Motivação Toponímica}

Os resultados relacionados à motivação toponímica apresentaram que 38,7\% remetem à ideia de um Fragmento florestal inundado; 35,7\%, Fragmento Florestal; 15,5\%, Depressão; 7,1\%, Depressão com fragmento florestal e 3\% para Lagos e Lagoas.

Foi necessário distinguir o "Fragmento florestal inundado" e "Depressão com fragmento florestal", devido à ênfase do significado. Fragmento florestal inundado é retratado como uma área alagada e coberta por vegetação. Já a Depressão com fragmento florestal está relacionado com a ideia de cavidade (sujeita à inundação), pouco profunda e coberta parcialmente com vegetação.

Nota-se que $85,5 \%$ das motivações toponímicas identificadas em trabalhos acadêmicos na Planície do Araguaia, para o referente "drepressão doliniforme", estão relacionadas com 
superfícies rebaixadas do terreno sujeitas à inundação (Hidrotopônimo), sendo cobertas com ou não por vegetação (Fitotopônimo).

\section{Taxonomia}

Buscando sistematizar o objeto denominado em macroestruturas que o classifiquem com relação à sua aplicação, foram categorizados todos os significados relacionados ao referente "depressão doliniforme", com base nos dois grupos de classificação: Taxonomias de Natureza Física e Taxonomias de Natureza Antropocultural.

As Taxonomias de Natureza Física foram as mais frequentes (97\%) como destaque para os: fitotôponimos (40,9\%); geomorfotôponimos (11,2\%), fitotopônimo / hidrotopônimo (10,6\%), fitotopônimo / geomorfotopônimo (9,0\%) e hidrotopônimo $(8,4 \%)$.

Os fitotôponimos foram os mais frequentes (40,9\%), com significados atrelados a "fragmentos florestais", demostrando que a aplicabilidade dos conceitos relacionados às "depressões doliniformes" na Planície do Araguaia estão associados a trabalhos de cunho vegetal, como: Caracterização Fitossociologica e Taxonomia Vegetal.

No entanto, percebe-se que há uma forte relação da aplicação do significado às áreas relacionadas à: Geomorfologia, Hidrologia e Fitossociologia. Entre os Geomorfotôponimos ressaltam-se os significados que definem o referente como: "depressóes naturais do terreno" e "rebaixamentos do solo".

A relação entre fitotopônimos / hidrotopônimos é enfatizada constantemente na acepção: "Os fragmentos florestais naturais são alagados sazonalmente". Os fitotopônimos / geomorfotopônimos são evidenciados em: "Os fragmentos florestais ocorrem em depressões naturais". Já os hidrotopônimos ressaltam o traço acidente hidrogeográfico, comparando-o a "lagoa" e "lago", sendo sua origem associada à elevação do lençol freático ou sujeitas à inundação sazonal.

Em menor proporção (3\%) do total das taxonomias, foram identificadas como de Natureza Antropocultural, sendo identificadas duas classes: ecotopônimos (2\%) e ergotopônimos (1\%). Os ecotopônimos representaram habitações de modo geral, associado aqui a um lugar de proteção da flora e fauna. Já os ergotopônimos são caracterizados por elementos da cultura material, simbolizando o lugar como "armadilha", lugar de caça ou fonte de alimento.

\section{Procedência do conhecimento do nomeador}

Com relação à procedência do conhecimento, observou-se que $(52,9 \%)$ dos significados analisados foram nomeados com base no conhecimento científico, ou seja, inferência adquirida com base na aplicação de métodos científicos e comparação de resultados.

Já o conhecimento empírico apresentou 38,7\% das inferências relacionadas a hipóteses, (sendo necessária a analise metodológica cientifica para sua corroboração). Entre as hipóteses mais recorrentes, encontram-se associadas ao topônimo ipuca com relação a sua gênese: "Os fragmentos florestais inundados usualmente são associados a depressões do terreno" também se destacam várias hipóteses quanto à sua composição florística: “As ipucas são identificadas como 
—Florestas Estacionais Semideciduais Aluviais" (Martins et al. 2006); ou "ipucas are unique forest fragments situated in the open fields of Cerrado vegetation and occur only in the Araguaia plains of state of Tocantins" (Rosa et al. 2006); ou “As ipucas (capões de mata envoltos por vasta matriz de cerrado)" (Pinheiro e Dornas 2009).

Com relação ao conhecimento Popular, 6,8\% das inferências analisadas vinculam a étimos de natureza indígena de origem Tupi (ipuca e impuca), relacionados a fragmentos de vegetação frequentemente denominados com base no conhecimento regional. $\mathrm{O}$ uso do étimo impuca apresentou-se recorrente em estudos realizados no estado de Mato Grosso, constatada na caracterização fitossociológica do município de Cocalinho em: "Capões - esta fitofisionomia é denominada localmente como impuca" (Marimon e Lima 2001). Já a tipologia ipuca é popularmente utilizada no Tocantins e tem seu uso frequente em inventários florestais, realizados no município de Lagoa da Confusão, como demonstrado em: "Fragmentos florestais naturais são chamados regionalmente de ipucas" (Brito et al. 2008).

\section{Rede Interdisciplinar}

A classificação dos temas abordados nos 66 trabalhos acadêmicos apresentou a seguinte distribuição: 33\% Fitossociologia; 10,5\% Geomorfologia; 10,5\% Sensoriamento Remoto; 8\% Caracterização ambiental; 7,5\% Análise Geoambiental; 7,5\% Taxonomia de Leveduras; 6\% Taxonomia de mamíferos; 5\% Antropologia Indígena; 3\% Taxonomia de repteis; 3\% Dinâmica territorial; 3\% Limnologia; 1,5\% Conservação de aves e 1,5\% Estudos Sociais.

A rede de análise, elaborada a partir da matriz de adjacência, demostrou que dos 66 trabalhos analisados, 62 estão vinculados entre si, por meio de citações, com o uso de significados próximos para o referente, denominado "depressão doliniforme" Figura 3. Os 4 trabalhos restantes não apresentaram vínculos (citações), mas verificam-se fortes relações semânticas entre os significados usados pelos outros autores. 
Figura 3. Vinculações disciplinares e interdisciplinares de trabalhos acadêmicos relacionados ao referente "depressão doliniforme" na Planície do Araguaia, no período de 1985 a 2019.

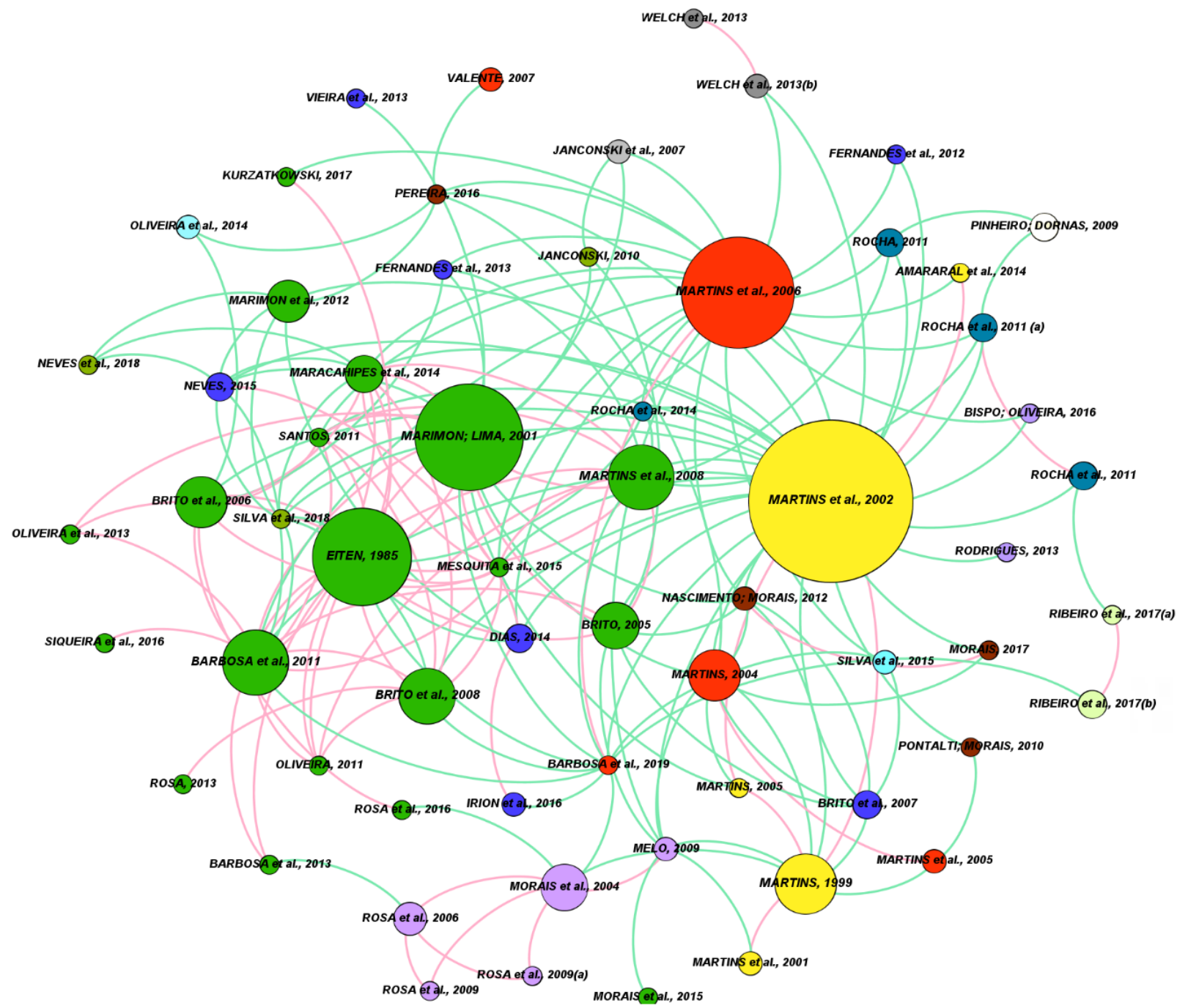

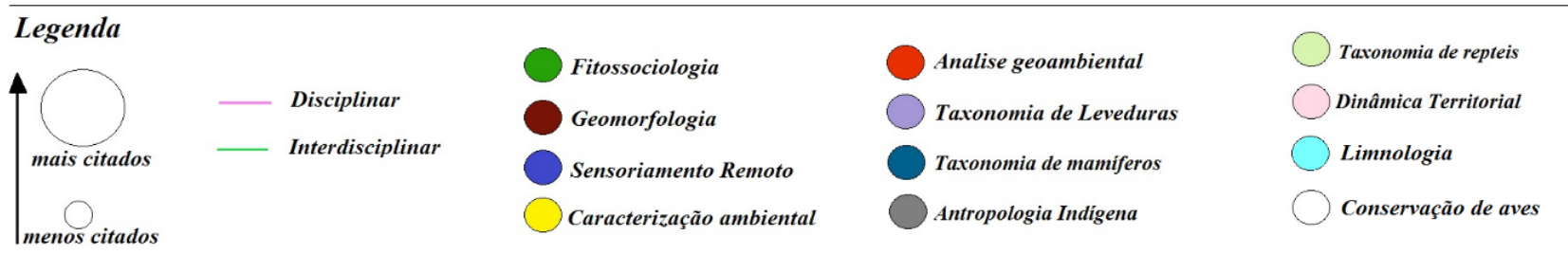

A vinculação ou conexão analisada, por meio das citações, comprovou que os trabalhos acadêmicos mais citados (nós maiores) referem-se a Martins et al. (2002), com 37 vinculações; Martins et al. (2006) com 20 vinculações; Marimon e lima (2001) com 19 vinculações; e Eiten (1985) com 17 vinculações.

Analisando a frequência das vinculações e as contribuições semânticas de Maritins et al. (2002), verifica-se que, neste trabalho (diagnostico ambiental), são ressaltados os resultados e as primeiras referências à ipuca, propostos por Martins (1999), definidos como fragmentos florestais naturais, localizados no município de Lagoa da Confusão, Estado do Tocantins (porção leste da Planície do Rio Araguaia). Com base na definição proposta e verificando que $92 \%$ dos vínculos (linha verde) se relacionam com diferentes temas (nós de outras cores), constata-se que há uma integralização do 
significado usado pela autora em diferentes áreas do conhecimento. Considera-se, desta forma, o uso da designação toponímica ipuca de natureza interdisciplinar.

A análise geoambiental, elaborada por Martins et al. (2006), estabelece uma forte ligação entre a designação e as definições usadas por Martins et al. (2002), devido à utilização da mesma área de estudo (município de lagoa da confusão, estado do Tocantins) e os mesmos coautores. Porém, o estudo da dinâmica ambiental é realizado sobre outra perspectiva, desde o ponto de vista geológico, pedológico e geomorfológico. Neste sentido, identificamos que os solos das ipucas são formados por sedimentos fluviais holocênicos, sobrepostos em rochas calcárias do Grupo Tocantins, que sofrem alta influência do lençol freático e acúmulo de uma rica camada de matéria orgânica de natureza ácida. Os autores pressupõem que o modelo de evolução dos solos desses fragmentos florestais naturais está relacionado com a dissolução, subsidência ou colapso de carste subjacente. Considerando a rede de análise e a proximidade com trabalhos na mesma área de estudo, verifica-se que $80 \%$ das vinculações também estão relacionadas com outros temas, reforçando assim o uso de ipuca como interdisciplinar.

O estudo Fitofisionômico de Marimon e Lima (2001) apresenta a caracterização da vegetação do município de Cocalinho, Estado de Mato Grosso (porção oeste da Planície do Rio Araguaia), o qual é complementado pelos inventários florísticos, realizados por Eiten (1985), sendo ele o responsável, pela primeira vez, pela nomeação impuca.

A contribuição semântica, observada em Marimon e Lima (2001), indica que a nomeação impuca teve como procedência o conhecimento regional (popular) e está relacionada à fitofisionomia de Capões (metonímia). É caracterizada por solos de coloração escura e textura argilosa, com drenagem deficiente (sujeitas a inundação sazonal), ocorrendo dentro de Campos limpos, sobre a forma de bacias. Sua composição florística é pouco diversa, prevalecendo a espécie Licania cf. parvifolia e algumas espécies de Matas inundáveis.

Analisando a rede social com os trabalhos relacionados com a nomeação impuca e seu significado, verifica-se que Marimon e Lima (2001) apresentam 70\% dos vínculos a mesma área de conhecimento (linha rosa), destacando-se os temas de Fitossociologia e a caracterização da vegetação por meio de sensores remotos (Sensoriamento Remoto). Já o estudo de Eiten (1985) se destacou por apresentar $88 \%$ das vinculações a trabalhos com o mesmo tema (Fitossociologia). Portanto, verifica-se que o uso de impuca está constantemente relacionado a trabalhos de cunho disciplinar na Planície do Araguaia.

\section{Discussão}

Com base nos resultados obtidos é possível observar que o referente, "depressão doliniforme", apresenta duas tipologias amplamente aceitas pela comunidade acadêmica e frequentes (40,9\%) em trabalhos de índole vegetal (Fitotopônimos). Ipuca foi nomeado por meio de um significado amplo, proporcionado sua aplicação semântica em várias áreas do conhecimento (interdisciplinar). Já impuca se origina de um significado restrito à fitofisionomia vegetal, consequentemente mais utilizado de forma disciplinar.

Porém, pela análise documental foi constatada semelhança e ampliação do significado de ipuca e impuca, nas áreas de estudo mais recorrentes (Fitossociologia e Geomorfologia), assim como casos de comprometimento semântico na aplicação interdisciplinar. Visando ressaltar 
a contribuição semântica dos autores e a universalização da aplicação das nomeações, serão descritos as acepções mais recorrentes de ipuca e impuca, em função dos temas abordados nos trabalhos acadêmicos.

\section{Fitossociologia}

Iрuca e impuca são topônimos motivados por características majoritariamente fitológicas e nomeados popularmente nos estados de Mato Grosso e Tocantins, região da Planície do Araguaia. O significado fitossociológico é atribuído a fragmentos naturais de floresta inundável, sazonalmente inundados, localizados em Campos sujos e limpos (varjão sujo e limpo) (Brito et al. 2008; Martins et al. 2008; Welch et al. 2013), sua distribuição na paisagem campestre ocorre em forma de manchas ovaladas ou circulares (Martins et al. 2006; Barbosa et al. 2011). Possuem baixa riqueza florística (Marimon e Lima 2001; Martins et al. 2001), as espécies de menor porte correspondem às arbustivas e lianas (Santos 2011; Oliveira et al. 2013). Os indivíduos arbóreos de maior frequência são tolerantes aos pulsos de inundação, destacando-se a dominância de Calophyllum Brasiliense (Landi); Sclerolobium paniculatum (Carvoeiro) e Licania apetala (farinha-seca) (Eiten 1985; Brito et al. 2006; Barbosa et al. 2019).

\section{Geomorfologia}

Os fragmentos florestais, nomeados ipucas e impucas, ocorrem em depressões naturais do terreno (Nascimento e Morais 2012; Maracahipes et al. 2014; Silva et al. 2015) com alta influência do lençol freático (Martins et al. 2002), formando bacias circundadas por vegetação (Marimon e Lima 2001; Dias 2014), na sua composição litológica superficial prevalecem sedimentos finos como argila e silte, além de frequentes depósitos de matéria orgânica no seu interior (Irion et al. 2016; Barbosa et al. 2019). As ipucas e impucas tendem a coalescer por processos associados à dissolução e subsidência de substrato calcário subjacente do Grupo Tocantins, formando dolinas e uvalas (Martins et al. 2006).

A associação de dolinas a impucas no estado de Mato Grosso é evidenciada como afundamentos do terreno com forma de dolinas ou meandros abandonados, constantemente úmidos, sobre os quais ocorrem espécies florestais toleráveis à inundação (Marimon et al. 2008).

No estado do Tocantins, as ipucas também foram visualizadas em depressões cársticas em: "Dolina em área de cultivo de arroz, formada pela subsidência recente (colapso) de uma ipuca" (Martins et al. 2006). Na mesma região, foi constado que: "as áreas com ocorrência de fragmentos florestais que, a partir da observação de imagens de satélite, da leitura de relatórios geológicos e de trabalhos de campo, mostraram-se tratar nitidamente de dolinas" (Morais 2017) (Figura 4). 
Figura 4. Ilustração de uma feição doliniforme denominada de ipuca/impuca localizada no município de Lagoa da Confusão-TO. A: Fotografia parte externa. B: Fotografia parte interna da feição. C: Visão aérea da feição (Lat. $-10.53^{\circ}$; long. $-49.39^{\circ}$ ).
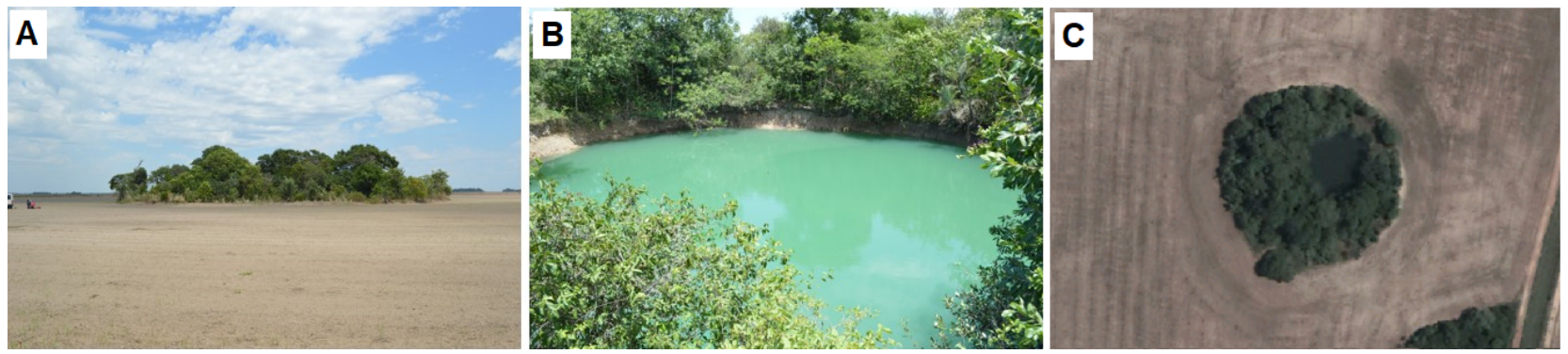

Fonte: Fotografias A e B do autor (Fernando Morais); C: Imagem do Google Earth (acesso: 7/05/2021)

\section{Extensão semântica no contexto interdisciplinar}

Considerando a relação dos fragmentos florestais com as dolinas, é necessário ressaltar que a ocorrência de depressões cársticas na Planície do Araguaia se apresenta também sobre a forma de lagos e lagoas (parcialmente cobertas ou sem vegetação).

Estudos geomorfológicos no município de Cocalinho/MT, onde há a ocorrência fragmentos de vegetação denominados impucas e ipucas (Marimon e Lima 2001; Welch et al. 2013), foram identificadas dolinas e uvalas, denominadas como lagoas, em ambientes cársticos e caracterizadas em estudos prévios por Soubies e Guyot (1995) posteriormente corroborados por Hardt (2004; 2005).

Parte da região de Cocalinho/MT é caracterizada por um relevo cárstico sobre forma de "cavernas, torres, dolinas e vertentes abruptas", localizadas próximas a uma Serra de Calcário, ao oeste do Rio das Mortes (tributário principal do Rio Araguaia). Nesta área, encontram-se uma série de lagoas alinhadas no mesmo sentido dos planos de falhas (W-SW e E-NE). Entre as lagoas, destacam-se: a Lagoa Grande, dolina formada pela dissolução de morros carbonáticos, pouco profunda e perfeitamente circular; e a Lagoa do Vânico, uvala formada pela dissolução de três dolinas e posicionada na mesma direção dos morros da Serra do Calcário (Hardt 2005).

A associação (metonímia) existente entre "lagoa" a impuca pode ser evidenciada também em trabalhos de fitossociologia, quando ocorre a retirada da vegetação no fragmento florestal "ocorreram evidências de perturbação antrópica através da retirada seletiva de Calophyllum brasiliensee do pastoreio extensivo que ocasiona trechos de erosão às margens dos "lagos", nos pontos de acesso do gado à água (bebedouros aturais) (Marimon e Lima 2001).

Estudos etonoecologicos, realizados no Parque Estadual do Araguaia/TO, também associam as impucas a fragmentos de vegetação sempre verde (Eiten 1985), como “lagoas" ou "ilhas", evidenciando sua forma circular:

"As "lagoas" são fragmentos naturais compostos basicamente por herbáceas e gramíneas. As "ilhas" são porções topograficamente mais baixas e próximas aos rios, que mantém-se verdes mesmo no período da seca. Na realidade, não são 'ilhas' no sentido geográfico, mas ilhas de vegetação sempre-verde” (Janconski et al. 2007). 
No estado do Tocantins, município de Lagoa da Confusão, onde foi caracterizada a maior parte das formações florestais denominadas ipucas (Martins et al. 2002; Brito et al. 2006), ocorrem também ambientes cársticos originários de fáceis calcário-dolomitica do Neoproterozóico caracterizados por lagoas em dolinas (lagoa da confusão) e cavidades subterrâneas (Valente 2007). As feições cársticas observadas na região correspondem a cavernas, mogotes, lapiás e dolinas (Pontalti e Morais 2010).

Análises morfométricas das ipucas demostraram que 90\% das feições da região de Lagoa da Confusão possuem formas circulares, deprimidas e estão orientadas no mesmo alinhamento das falhas geológicas (Nascimento e Morais 2012; Pereira 2016).

Pressupõe-se, portanto, que pode existir uma forte relação entre a formação dos fragmentos de vegetação, denominados impuca e ipuca, com a origem dos lagos e lagoas, associadas a dolinas na Planície do Araguaia.

A presença de fragmentos florestais em depressões cársticas fechadas é evidenciada em outros países, destes, destacasse a semelhança paisagística das depressões doliniformes da Planície do Araguaia (Estado Tocantins e Mato Grosso) com os campos de dolinas (sinkhole plain) nos Estados Unidos, Estado Illinois, Planície de hidrográfica do Rio Mississipi (Figura 5).

Figura 5. Comparação das áreas de estudo com ipucas no Brasil e (Dolinas) Sinkholes nos Estados Unidos. A: Ipucas localizadas na Planície do Araguaia, município de Lagoa da Confusão, Brasil, área de estudo de Martins et al., 2002 (Lat. $-10.85^{\circ}$; long. $-49.75^{\circ}$ ). B: "Sinkholes" localizados na Planície do Rio Mississipi, estado de Illinois, Estados Unidos, área de estudo de Angel, Nelson e Panno, 2004 (Lat. 38.22 ${ }^{\circ}$; long. $\left.-90.18^{\circ}\right)$
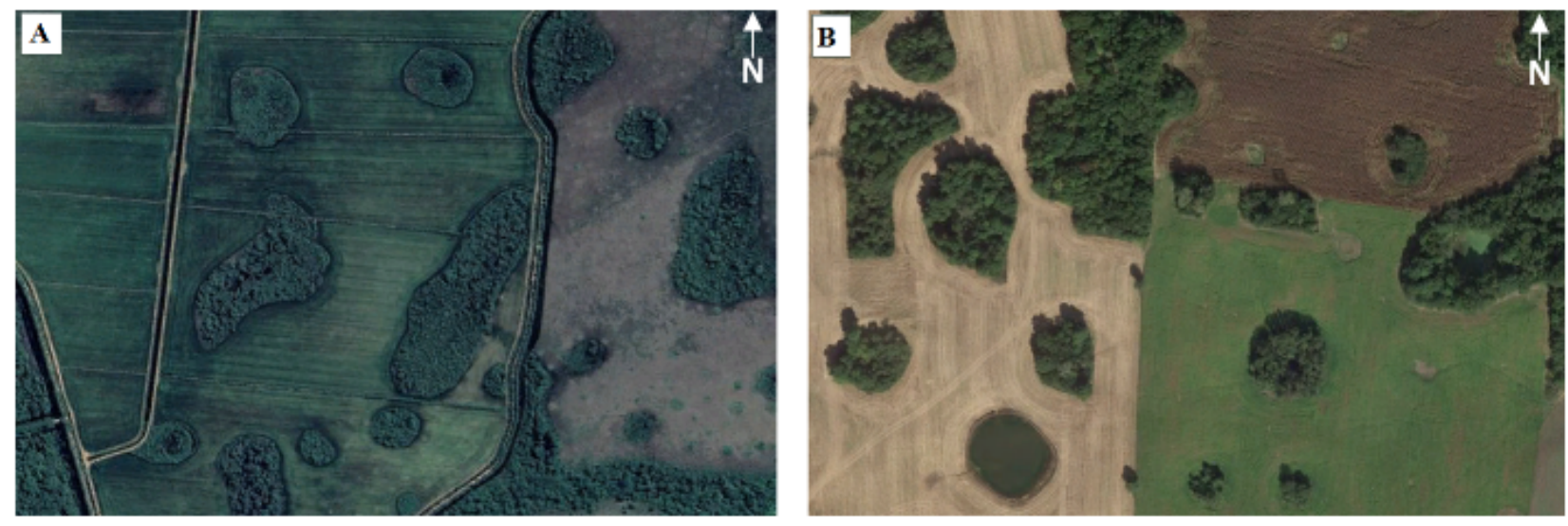

Fonte: Imagens do Google Earth (acesso: 7/04/2020)

Os estudos relacionados à análise espacial da densidade de dolinas (Sinkhole density) na Planície de inundação do Rio Mississipi/EUA, localizada no sudoeste de Illinois, identificaram mais de 10.000 dolinas (sinkholes), caracterizadas como depressões, aglomerados de arvores e lagoas "Sinkholes are marked by depressions, tree clusters, and ponds" (Angel et al. 2004). Os autores ressaltam que os estudos de densidade e distribuição de dolinas são necessários para avaliar o grau de carstificação, identificação de áreas de risco de subsidência e contenção dos possíveis impactos relacionados à contaminação de águas subterrâneas em ambientes antropizados.

A relação de dolinas com fragmentos florestais sujeitos à inundação também é identificada em mapeamentos de vegetação riparia ao redor de dolinas, localizadas na Bacia Hidrografia do Rio Azul (Blue River watershed), estado Luisiana, Estados unidos. Neste, é classificada a vegetação 
presente nas depressões como: "Deciduous forest", caracterizada por espécies arbóreas adaptadas a inundação sazonal (Copler 2017). Comunidades homogêneas de grupos arbóreos, tolerantes aos ciclos hidrológicos, também foram identificados no interior de dolinas (sinkholes) no centro-oeste do estado da Florida, Estados Unidos (Fetterman et al. 2003).

A tendência de indivíduos arbóreos colonizarem áreas úmidas sobre forma de "manchas", como em dolinas, está relacionado capacidade morfoanatômica de suportar baixas concentrações de oxigênio em ambientes submersos (Marques e Joly 2000). Na Planície do Araguaia, os regimes de inundação sazonal favorecem o surgimento alguns ambientes alagados cobertos por vegetação, sob a forma de manchas, denominados impuca e ipuca, nos quais é destacada a dominância da espécie Calophyllum brasilience (popularmente denominado "landi") que devido às suas características morfológicas, adapta-se facilmente ambientes inundados e é frequentemente identificada em regiões tropicais (Barbosa et al. 2011).

Quanto à subjetividade da forma "mancha" no contexto da paisagem, é importante ressaltar que a formação florestal denominada ipuca apresenta formas alongadas, de 5 hectares até 100 hectares de extensão (Martins et al. 2002). Essas vastas formações florestais podem ser classificadas como Unidade de Vegetação Arbustivo-Arbórea associada inativos paleocanais aluviais ou paleomeandros amplamente distribuídos na Planície do Araguaia (Latrubesse e Stevaux 2002). A topografia do terreno e a influência da dinâmica fluvial em "meandros abandonados e/ou colmatados" (Oxbows) favorecem a deposição de matéria orgânica sobre substratos areno-argilosos, criando ambientes propícios para a fixação vegetal (Morais et al. 2008).

Entre as outras formas de "manchas" de vegetação, identificadas na paisagem da Planície do Araguaia, encontram-se os Campos de Murundus. Denominados como fragmentos florestais circulares em forma de "montes de terra", relacionados com o soerguimento do solo originado por fatores abióticos como a erosão diferencial e bióticos pela colonização de termiteiros (Marimon et al. 2012).

\section{Conclusões}

O referente "depressão doliniforme" apresenta três variações toponímicas geralmente aceitas em trabalhos acadêmicos, realizados na Planície do Araguaia. As nomeações toponímicas, ipuca e impuca, foram as mais recorrentes (64,3\% e 25,3\%), assim como: dolina (6,8\%) ou Sinkhole, esta última amplamente usada pela comunidade acadêmica internacional.

Quanto à motivação toponímica, por meio da ficha lexicográfica-toponímica, foi constatado que ipuca e impuca estão relacionadas a Fitotôponimos (40,9\%), ou seja, são topônimos associados a realidades de índole vegetal, sendo que $38,7 \%$ dos significados identificados remete à ideia de Fragmento Florestal inundado. Na língua Tupi, tal conotação pode ser interpretada como "água aberta”, "água que arrebenta".

Pela Rede de Análise Social foi possível identificar que os trabalhos mais citados por diferentes áreas de conhecimento estão vinculados ao topônimo ipuca ( $92 \%$ de vínculos de outros temas), classificada, desse modo, como Interdisciplinar. Já impuca é frequentemente usada em estudos fitossociológicos, apresentando $88 \%$ das vinculações a trabalhos de índole vegetal, classificada, portanto, como disciplinar. 
Os topônimos ipuca e impuca apresentaram diferenças nos aspectos semânticos de natureza interdisciplinar. Foi constatado, pela análise documental de trabalhos acadêmicos, que alguns fragmentos florestais, denominados ipuca ou impuca, estão fortemente relacionados com estruturas fechadas de ambientes cársticos, denominadas dolinas (sinkholes).

Desta forma, é importante que as ações realizadas nos fragmentos de florestais inundados, denominados ipuca ou impuca, levem em consideração as seguintes recomendações:

a) Espécies arbóreas tropicais pioneiras, como Calophyllum brasilience, apresentam adaptação morfoanatômica para ambientes alagados. Assim, fragmentos florestais inundáveis na Planície do Araguaia, como ipucas ou impucas, podem ocorrer em meandros abandonados ou colmatados do tipo oxbows, como também, em dolinas ou uvalas presentes em ambientes cársticos.

b) Fragmentos florestais denominados ipucas não ocorrem somente no estado do Tocantins. Portanto, Espécies denominadas como endêmicas, das ipucas do Tocantins, como Rhipidomys ipukensisn. sp., podem ocorrer habitats semelhantes, como no estado de Mato Grosso. Refutando as hipóteses propostas por Ribeiro et al. (2017) e Rocha et al. (2011).

c) Na caracterização ambiental, por meio de sensores remotos, recomenda-se o uso de métodos geoelétricos que ratifiquem as hipóteses relacionadas à morfogênese das depressões, assim como o uso de Modelos Digitais do Terreno de alta precisão que diferenciem os fragmentos florestais em depressões doliniformes de soerguimentos litológicos circulares com vegetação (Murundus).

d) Nas ações de recuperação de áreas degradadas dentro de fragmentos de vegetação, denominados ipucas, propostos por Amaral et al. (2004), devem, necessariamente, levar a consideração a presença de dolinas sujeitas à subsidência ou colapso de rochas carbonáticas subjacentes do Grupo Tocantins. A sobrecarga de espécies arbóreas no interior destas depressões pode acelerar os processos cársticos, causando perdas progressivas de solo.

Considerando a forte relação dos fragmentos florestais com as dolinas é necessário reavaliar as ações de preservação e planejamento regional próximas a áreas de agricultura intensiva. A conexão entre as depressões fechadas cársticas e os sistemas de água subterrâneos permite que essas feições funcionem como uma unidade de recarga de aquíferos, habitat de espécies adaptadas à inundação e corredor ecológico entre o ecótono do bioma cerrado e amazônico. Desta forma, o uso não planejado destas áreas pode aumentar o risco de contaminação de água subterrânea pela solubilização de defensivos agrícolas e acelerar os processos de dissolução de rochas subjacentes, modificando os habitats de espécies endêmicas da região.

Participação dos autores: OEPM - redação principal do texto, correções, coleta de dados, confecção de gráficos e tabelas. FM - Orientador da proposta de estudo, auxílio na interpretação, discussão dos resultados, redação científica do artigo, revisão final do artigo; KSA - Orientadora da proposta de estudo, orientação metodológica, auxilio na interpretação dos dados, responsável pela revisão conceitual, ajustes, formatação e redação científica.

Aprovação ética ou licenças de pesquisa: não se aplica

Disponibilidade dos dados: os dados coletados não estão depositados em nenhum banco de dados ou repositório.

Fomento: não houve financiamento.

Conflito de Interesses: os autores declaram não haver conflitos de interesse. 


\section{Referências}

Amaral RVD, Lopes JC, Pedreira PRP, Azevedo AAD. 2014. Recuperação de áreas degradadas de fragmentos florestais (ipucas) no cerrado, na bacia hidrográfica do rio formoso. Natal-RN, SRHN, p. 1-10.

Angel JC, Nelson DO, Panno SV. 2004. Comparison of a new gis-based technique and a manual method for determining sinkhole density: an example from illinois' sinkhole plain. Journal of Cave and Karst Studies 66(1):9-17. Disponivel em: http://www.seopanel.esforums.caves.org/pu b/journal/PDF/V66/v66n1-Angel.pdf

Barbosa DCD, Marimon BS, Lenza E, Marimon JBH, Oliveira EA, Maracahipes L. 2011. Estrutura da vegetação lenhosa em dois fragmentos naturais de florestas inundáveis (impucas) no Parque Estadual do Araguaia, Mato Grosso. Revista Árvore 35(3): 457-471. https://doi.org/10.1590/S0100-67622011000300009

Barbosa MVM, Fernandes TA, Siqueira GB, Siqueira FLT, Morais PB. 2019. Spatial Variability of the Physicochemical Properties of Soils from Seasonally Flooded Forest Fragments on a Tropical Plain. Applied and Environmental Soil Science. p. 8. https://doi.org/10.1155/2019/1814937

Bondesan A, Meneghel M, Sauro U. 1992. Morphometric analysis of dolines. International Journal of Speleology 21(1): 1. https://scholarcommons.usf.edu/ijs/vol21/iss1/1/

Bordin AS, Gonçalves AL, Souza JA, Borges MA, Inomata DO. 2015. Identificação e análise de comunidades de colaboração científica: estudo de caso em um programa de pós-graduação interdisciplinar. Perspectivas em Gestão \& Conhecimento 5:109-126. https://dialnet.unirioja .es/servlet/articulo? codigo=5213850

BRASIL. 1981. Projeto RADAMBRASIL. Folha SC. 22. Tocantins: Geologia, geomorfologia, pedologia, vegetação e uso potencial da terra. Ministério das Minas e Energia. Secretaria Geral. Rio de Janeiro, p. 524.

Brito ER, Martins SV, Oliveira Filho ATD, Silva E, Silva AFD. 2006. Estrutura fitossociológica de um fragmento natural de floresta inundável em área de orizicultura irrigada, Município de Lagoa da Confusão, Tocantins. Revista Árvore 30(5): 829-836. https://doi.org/10.1590/S0100-67622006000500017

Brito ER, Martins SV, Oliveira Filho ATD, Silva E, Silva AFD. 2008. Estrutura fitossociológica de um fragmento natural de floresta inundável em área de Campo Sujo, Lagoa da Confusão, Tocantins. Acta Amazonica 38(3): 379-386. https:// doi.org/10.1590/S0044-59672008000300002

Copler C. 2017. Riparian Buffered Sinkholes in the Blue River Watershed. Undergraduate Thesis - Bellarmine University. Louisville, p. 51.

Dias AP. 2014. Análise espacial aplicada à delimitação de áreas úmidas da planície de inundação do Médio Araguaia. Dissertação (Mestrado em Ciências Florestais e Ambientais)- UFMT.

Dick MV. 1992. Toponímia e Antroponímia no Brasil. Coletânea de Estudos. 3. ed. São Paulo.

Dick MV. 2004. Rede de conhecimento e campo lexical: hidrônimos e hidrotopônimos na onomástica brasileira. In: ISQUERDO, A. N.; KRIEGER, M. D. G. As ciências do léxico: lexicologia, lexicografia, terminologia. Campo Grande, MS: UFMS. 2: 121-130.

Eiten G. 1985. Vegetation near Santa Teresinha, NE Mato Grosso. Acta Amazonica 15(3-4): 275-302.. https://doi. org/10.1590/1809-43921985153301

Fetterman PPG, Bell H, Lawhorne D. 2003. Vegetative communities and morphological characteris-tics of selected sinkholes in west-central florida. Karst Studies in West Central Florida, p. 65-77. http://citeseerx.ist.psu.edu/viewdoc/ download?doi=10.1.1.518.4349\&rep=rep1\&type=pdf

Fonseca GS. 1997. La gente pasa, los nombres quedan. Introduccíon a la toponímia. Lima: Lengua e Sociedad.

Ford D, Williams P. 2007. Karst Hydrogeology and Geomorphology. 2 ed. West Sussex, England: John Wiley \& Sons. 
Gutiérrez F, Guerrero J, Lucha P. 2008. A genetic classification of sinkholes illustrated from evaporite paleokarst exposures in Spain.. Environmental Geology 53(5):993-1006. https://doi.org/10.1007/s00254-007-0727-5

Hardt R. 2004. Aspectos da morfologia cárstica da Serra do Calcário - Cocalinho - MT. Dissertação (mestrado) UNESP. Rio Claro-SP.

Hardt R. 2005. Considerações geomorfológicas sobre o carste de cocalinho - MT. Campinas-SP, Sociedade Brasileira de Espeleologia, p. 66-76.

Irion G, Nunes GM, Nunes-da-Cunha C, Arruda EC, Santos TM, Dias AP, Junk WJ. 2016. Araguaia River Floodplain: Size, Age, and Mineral Composition of a Large Tropical Savanna Wetland. Wetlands 36(5): 945-956. https://doi.org/10.1007/ s13157-016-0807-y

Jancoski HS, Marimon BS, Marimon-Júnior B, Franczak DD, Lima HS. 2007. Aspectos etnoecológicos do parque estadual do araguaia-mt como subsídios para delinear estratégias de uso e conservação. In: Anais do VIII Congresso de Ecologia do Brasil. Caxambu - MG: Sociedade de Ecologia do Brasil. p. 1-2.

Kurzatkowski D, Leuschner C, Homeier J, 2015. Effects offlooding on trees in the semi-deciduous transition forests of the Araguaia floodplain, Brazil. Acta Oecologica 69:21-30. https://doi.org/10.1016/j.actao.2015.08.002

Latrubesse EM, Stevaux JC. 2006. Características físico-bióticas e problemas ambientais associados à Planície Aluvial do Rio Araguaia, Brasil Central. Revista Geociências-UNG 5(1): 65-73. http://revistas.ung.br/index.php/geociencias/ article/view/97

Lopes MH, Franco JLDA, Costa KS. 2017. Expressões da Natureza no Parque Nacional do Araguaia: Processos geoecológicos e diversidade da vida. Historia Ambiental Latinoamericana y Caribeña (HALAC). Revista de la Solcha 7(2): 65-100. https://doi.org/10.32991/2237-2717.2017v7i2.p65-100

Magalhães-Filho LNL, Vergara FE, Rodrigues W. 2015. Cobrança pelo uso da água na bacia hidrográfica do rio Formoso - TO: Estudo de Viabilidade Financeira. Revista de Gestão de Águas da América Latina 12(1): 53-61. https://abrh.s3.saeast-1.amazonaws.com/Sumarios/185/7d0f1 4a09507598d31f5ea3d230ae083_c36fc22c3a99e49d05728f6d24c43fda.pdf

MAPBIOMAS. 2019. Projeto MapBiomas: Série Anual de Mapas de Cobertura e Uso de Solo do Brasil. https://mapbiomas. org . Acesso em: 1 Julho 2019.

Maracahipes L, Marimon BS, Lenza E, Marimon-Junior BH, Oliveira EA, Mews HA, Feldpausch TR. 2014. Post-fire dynamics of woody vegetation in seasonally flooded forests (impucas) in the Cerrado-Amazonian Forest transition zone. Flora-Morphology, Distribution, Functional Ecology of Plants 209(5-6): 260-270. https://doi.org/10.1016/j. flora.2014.02.008

Marimon BS, Marimon-Junior BH, Mews HA, Jancoski HS, Franczak DD, Lima HS, Moresco MC. 2012. Florística dos campos de murundus do Pantanal do Araguaia, Mato Grosso, Brasil. Acta Botanica Brasilica 26(1): 181-196. https://doi. org/10.1590/S0102-33062012000100018

Marimon BS, Lima ES. 2001. Caracterização fitofisionômica e levantamento florístico preliminar no pantanal dos rios Mortes-Araguaia, Cocalinho, Mato Grosso, Brasil. Acta Botanica Brasilica 15(2): 213-229. https://doi.org/10.1590/ S0102-33062001000200008

Marques MCM, Joly CA, 2000. Germinação e crescimento de Calophyllum brasiliense (Clusiaceae), uma espécie típica de florestas inundadas. Acta Botanica Brasilica 14(1): 113-120. https://doi.org/10.1590/S0102-33062000000100010

Martins AKE, Schaefer CEG, Silva E, Soares VP, Corrêa GR, Mendonça BAFD. 2006. Relações solo-geoambiente em áreas de ocorrência de ipucas na planície do médio araguaia - Estado de Tocantins. Revista Árvore 30(2): 297-310. https://doi.org/10.1590/S0100-67622006000200017

Martins ICM, Soares VP, Silva E, Brites RS. 2001. Caracterização ambiental de fragmentos florestais naturais - “ipucas”no Município de Lagoa da Confusão, Tocantins. In: Anais X Simpósio Brasileiro de Sensoriamento Remoto. Foz de Iguaçu. 
Martins ICM, Soares VP, Silva E, Brites RS. 2002. Diagnóstico ambiental no contexto da paisagem de fragmentos florestais naturais “ipucas” no município de Lagoa da Confusão, Tocantins. Revista Árvore 26(3): 299-309. https://doi. org/10.1590/S0100-67622002000300005

Martins ICM. 1999. Diagnostico Ambiental no contexto da paisagem de fragmentos florestais naturais "ipucas" no município de Lagoa da Confusão, Tocantins. Dissertação (Mestrado em Ciencias Florestais). Universidade Federal de Viçosa. Viçosa-MG, p. 97.

Martins SV, Brito ER, Oliveira-Filho ATD, Silva AFD, Silva E. 2008. Floristic composition of two wetland forests in araguaian plain, state of tocantins, brazil, and comparison with other areas. Revista Árvore 32(1): 129-141. https://doi. org/10.1590/S0100-67622008000100015

Morais RP, Aquino S, Latrubesse EM. 2008. Controles hidrogeomorfológicos nas unidades vegetacionais da planície aluvial do rio Araguaia, Brasil planície aluvial do rio Araguaia, Brasil. Acta Scientiarum-Biological Sciences 30 (4): 411 421. https://doi.org/10.4025/actascibiolsci.v30i4.5871

Morais F. 2017. Classificação morfológica das dolinas da região de Lagoa da Confusão - TO. In: Anais do 34 Congresso Brasileiro de Espeleologia. Ouro Preto-MG: Sociedade Brasileira de Espeleologia. p. 283-287.

Morais PB, Noleto-Júnior S, Martins ICM. 2017. Análise de sustentabilidade do projeto hidroagrícola Javaés/Lagoa, no Estado do Tocantins. Cadernos de Ciência \& Tecnologia 34(1): 83-111. http://dx.doi.org/10.35977/0104-1096.cct2017. v34.26297

Moreira DC, Collicchio E, Gamba FB. 2019. Panorama do cultivo e produtividade da soja na APA Ilha do Bananal/ Cantão, Tocantins: safras 2008/2009 a 2015/2016. Journal of Bioenergy and Food Science 6(4): 119-131. http://dx.doi. org/10.18067/jbfs.v6i4.262

Nascimento P, Morais F. 2012. Análise morfométrica em ipucas em carste encoberto na Depressão do Médio Araguaia, Estado do Tocantins. In: 9 SINAGEO - Simpósio Nacional de Geomorfologia. Rio de Janeiro: SINAGEO. p. 1-6.

Nunes VR, Andrade KS. 2012. O onoma e sua relação com a interdisciplinaridade nos parâmetros curriculares do ensino fundamental de geografia: um estudo preliminar com foco na toponímia. Revista Língua \& Literatura 14(23): 195-210. http://www.revistas.fw.uri.br/index.php/revistalinguae literatura/article/view/379

Oliveira EA, Marimon BS, Feldpausch TR, Colli GR, Marimon-Junior BH, Lloyd J, Phillips OL. 2014. Diversity, abundance and distribution of lianas of the Cerrado-Amazonian forest transition, Brazil. Plant Ecology \& Diversity 7(1-2): 231-240. https://doi.org/10.1080/1755 0874.2013.816799

Pereira GC. 2016. Contribuições à Geomorfologia da Lagoa da Confusão - TO. Dissertação (Mestrado) - Universidade Federal do Tocantins. Porto Nacional-TO, p. 125.

Pinheiro RT, Dorna T. 2009. Distribuição e conservação das aves na região do Cantão, Tocantins: ecótono Amazônia/ Cerrado. Biota Neotropica, 9(1). https://doi.org/10.1590/S1676-06032009000100019

Pocklington R. Introducción a la toponomástica - 1. Aspectos universales de la toponimia. Disponivel em: < https:// www.academia.edu/21713377/INTRODUCCI\%C3\%93N_A_LA_ _TOPONOM\%C3\%81STICA_-_1._ASPECTOS_ UNIVERSALES_DE_LA_TOPONIMIA >. Acesso em: 19 Set. 2019.

Pontalti AL, Morais F. 2011. Evolução geomorfológica da gruta Casa de Pedra, Lagoa da Confusão - TO. In: VIII Simpósio Nacional de Geomorfologia. p. 13.

R Core Team. R: 2019. A language and environment for statistical computing. R Foundation for Statistical Computing, Vienna, Austria. URL https://www.R-project.org/ .

Ribeiro J, Colli GR, Caldwell JP, Ferreira E, Batista R, Soares A. 2017. Evidence of neotropical anuran community disruption on rice crops: a multidimensional evaluation. Biodiversity and Conservation 26(14): 3363-3383. https://doi. org/10.1007/s10531-017-1410-0 
Rocha RG, Ferreira E, Costa B, Martins I, Leite YL, Costa LP, Fonseca C. 2011. Small mammals of the mid-Araguaia River in central Brazil, with the description of a new species of climbing rat. Zootaxa 2789(1):1-34. http://dx.doi.org/10.11646/ zootaxa.2789.1.1

Rosa CA, Morais PB, Lachance MA, Pimenta RS, Santos RO, Trindade RC, Figueroa DL. 2006. Candida azymoidessp. n., a yeast species from tropical fruits and larva (Ascomycota) of Anastrepha mucronota (Diptera: Tephritidae). Lundiana 7(2): 83-86. https://www2.icb.ufmg.br/lundian a/full/vol722006/1.pdf

Sampaio T. 1987. O tupi na geografia nacional. 5. ed. São Paulo: Brasiliana.

Santos L. 2011. Estrutura e dinâmica de florestas inundáveis (impucas) na transição Cerrado-Floresta Amazônica, leste de Mato Grosso, Brasil. Dissertação (Mestrado) - Universidade do Estado de Mato Grosso. Nova Xamantina.

Seara IC, Nunes VG, Lazzarotto C. 2011. Fonética e Fonologia do Português brasileiro. Florianópolis: LLV/CCE/UFSC. (2).

SEPLAN. 2012. Atlas do Tocantins: subsídios ao planejamento da gestão territorial. Secretaria de planejamento do estado do tocantins. Palmas, p. 79.

Silva HJ, Barbosa MVM. Morais PB. 2015. Estudos sazonais de aspectos limnólogicos de um fragmento florestal inundado na Planície do Araguaia, Tocantins, Brasil.. Journal of Bioenergy and Food Science 2(4): 239-248. http://dx.doi. org/10.18067/jbfs.v2i4.76

Soubies F, Guyot JL. 1995. Compte Rendu de Mission dans la Région du Rio das Mortes (Mato Grosso) du 5 au 8 Septembre 1995. ORSTOM. Brasilia, p. 6.

Teles EFB, Morais F. 2019. Gestão de áreas cársticas: uma proposta para a conservação ambiental. In: $35^{\circ}$ Congresso Brasileiro de Espeleologia, Bonito, 19-22.

Tibiriça LC.1984. Dicionário Tupi-Português. 2. ed. São Paulo: Traço Editora.

Valente CR. 2007. Controles físicos na evolução das unidades geoambientais da Bacia do Rio Araguaia, Brasil Central. Tese de Doutorado (Ciências Ambientais) - Universidade Federal de Goiás. Goiania-GO, p. 163.

Welch JR, Santos RV, Flowers NM, Coimbra CEA. 2013. Na primeira margem do rio: território e ecologia do povo Xavante de Wedezé. Rio de Janeiro: Museu do Índio-FUNAI. 